\title{
APRESENTAÇÃO GERAL DO CICLO DE PREMIAÇÃO 2003
}

\author{
Marco Antonio Teixeira e Paula Pedroti
}

(Membros da Equipe de Coordenação do Programa GESTÃo PÚBLICA E CIDADANIA)

Em 2003, na oitava edição do seu Ciclo de Premiação, o Programa Gestão Pública e Cidadania $(G P C)$, recebeu 1156 inscrições válidas, o que significou um incremento de $18 \%$ em relação às 981 experiências inscritas no ano anterior.

O banco de dados do Gestão Pública e Cidadania já acumula um total de 6.256 experiências de governos subnacionais enviadas por municípios, governos estaduais e organizações próprias dos povos indígenas. Na tabela 1, destaca-se a distribuição dos projetos por nível de governo desde 1996, ano em que se realizou o primeiro Ciclo de Premiação do GPC. Como pode ser observado, do total de inscrições em 2003, 1.056 (91\%) foram realizadas por municípios, $92(8 \%)$ efetuadas por governos estaduais e 8 (1\%) sob a responsabilidade de organizações próprias dos povos indígenas. Deve-se destacar que os programas de origem intermunicipal (12 inscrições) e do Distrito Federal (uma inscrição) foram incluídos, na tabela 1 , no nível municipal e os de caráter interestadual (duas inscrições) estão sendo apresentados com as inscrições efetuadas por governos estaduais.

TABELA 1 - Distribuição dos Projetos Inscritos por Nível de Governo

\begin{tabular}{|c|c|c|c|c|c|c|c|c|}
\hline $\begin{array}{l}\text { Nível de } \\
\text { Governo }\end{array}$ & $\begin{array}{r}1996 \\
(\%) \\
\end{array}$ & $\begin{array}{r}1997 \\
(\%)\end{array}$ & $\begin{array}{r}1998 \\
(\%) \\
\end{array}$ & $\begin{array}{r}1999 \\
(\%) \\
\end{array}$ & $\begin{array}{r}2000 \\
(\%)\end{array}$ & $\begin{array}{r}2001 \\
(\%)\end{array}$ & $\begin{array}{r}2002 \\
(\%) \\
\end{array}$ & $\begin{array}{r}2003 \\
(\%) \\
\end{array}$ \\
\hline Estadual & $134 / 21$ & \begin{tabular}{|l|l|}
122 & 41 \\
\end{tabular} & 22435 & \begin{tabular}{|l|l|}
157 & 18 \\
\end{tabular} & $123 \mid 13$ & $97 \quad 13$ & \begin{tabular}{|l|l|}
144 & 15 \\
\end{tabular} & \begin{tabular}{|l|l|}
92 & 8 \\
\end{tabular} \\
\hline Mun & 48878 & 17459 & 40063 & 72181 & 81486 & 62786 & 82484 & 105691 \\
\hline Indígena & $7 \quad 1$ & 10 & $7 \quad 1$ & & 91 & 41 & 131 & 81 \\
\hline Total & 629 & 297 & 631 & 888 & 946 & 728 & 981 & 1156 \\
\hline
\end{tabular}

Verifica-se que as iniciativas realizadas pelos municípios representam a maioria das inscrições em todos os Ciclos de Premiação. Em 1996, as unidades municipais participaram com $78 \%$ do total das inscrições. No ano de 1997 , registra-se uma queda 
significativa na participação percentual das inscrições de municípios, o que pode ser compreendido como uma consequiência das eleições para prefeito no ano anterior e também pelo fato de ainda não ser permitida a reeleição para os cargos eletivos do Poder Executivo ${ }^{1}$.

Desde o primeiro ciclo de premiação, em termos quantitativos, os programas enviados pelos governos estaduais apresentam uma média de 136,6 inscrições por ano, com pequenos decréscimos nos anos posteriores ao processo eleitoral para os executivos estaduais. Entretanto, com o aumento do número de inscrições de diferentes municípios, o peso relativo dos programas inscritos pelos governos estaduais tende naturalmente a diminuir sem que isso represente um declínio de interesse. Afinal, há 26 estados no Brasil (27 incluindo o Distrito Federal) e mais de 5.500 municípios. Em termos de jurisdição, os estados representam apenas $0,5 \%$ do país.

A participação percentual das inscrições enviadas pelas organizações próprias dos povos indígenas vem mantendo uma maior estabilidade no que se refere à participação percentual sobre o volume total de inscritos nos ciclos de premiação do GPC ao representarem, em praticamente todos anos, cerca de $1 \%$ do volume de inscrições.

Na tabela 2, destaca-se a divisão de todos os projetos e programas por grandes regiões, desde o primeiro Ciclo de Premiação.

TABELA 2 - Programas, Projetos e Atividades Inscritos, por Nível de Governo, Segundo a Região Geográfica

\begin{tabular}{|c|c|c|c|c|c|c|c|c|}
\hline & $\begin{array}{r}1996 \\
(\%)\end{array}$ & $\begin{array}{r}1997 \\
(\%)\end{array}$ & $\begin{array}{r}1998 \\
(\%)\end{array}$ & $\begin{array}{r}1999 \\
(\%)\end{array}$ & $\begin{array}{r}2000 \\
(\%)\end{array}$ & $\begin{array}{r}2001 \\
(\%)\end{array}$ & $\begin{array}{r}2002 \\
(\%)\end{array}$ & $\begin{array}{l}2003 \\
\quad(\%)\end{array}$ \\
\hline Centro-Oeste & 244 & $46 \quad 15$ & 53 & 18 & 36.4 & 22 & 55 & 31 \\
\hline Nordeste & $70 \quad 11$ & $\begin{array}{ll}61 & 21\end{array}$ & $\begin{array}{ll}60 & 10\end{array}$ & $116 \quad 13$ & $121 \quad 13$ & $102 \quad 14$ & $124 \quad 13$ & $195 \quad 17$ \\
\hline Norte & 173 & 8 & 264 & 38 & 21 & 29 & 45.5 & 41.4 \\
\hline Sudeste & 38461 & 12040 & $\begin{array}{ll}324 & 51\end{array}$ & $453 \quad 51$ & $\begin{array}{ll}435 & 46\end{array}$ & $\begin{array}{ll}357 & 48\end{array}$ & $\begin{array}{ll}502 & 51\end{array}$ & $520 \quad 45$ \\
\hline Sul & 13421 & $62 \quad 21$ & $168 \quad 27$ & $263 \quad 30$ & $333 \quad 35$ & $218 \quad 29$ & $255 \quad 26$ & 36932 \\
\hline Total & 629 & 297 & 631 & 888 & 946 & 742 & 981 & 1156 \\
\hline
\end{tabular}

Ao todo, verifica-se, que no decorrer desses oito anos do Programa Gestão Pública e Cidadania, o peso percentual da participação das grandes regiões geográficas brasileiras no envio de inscrições ao prêmio GPC vem apresentando uma relativa estabilidade.

\footnotetext{
${ }^{1}$ A Emenda Constitucional que permitiu a reeleição para cargos eletivos do Executivo passou a vigorar em 1998.
} 
Em relação à distribuição dos programas e projetos enviados pelos governos estaduais, prefeituras e organizações próprias dos povos indígenas segundo as grandes áreas geográficas, os dados da tabela 2 permitem verificar que as regiões Sudeste e Sul foram, respectivamente, as mais representadas em todos os ciclos de premiação. Ambas somaram em 1996 um total de 83\% das inscrições, e no ano de 2003 atingiram o patamar de $77 \%$.

Destaca-se ainda uma pequena oscilação positiva na participação das inscrições provenientes da região Nordeste que saltou de 11\% do total em 1996 para 17\% em 2003. Nas regiões Centro-Oeste e Norte, onde se apresentam as menores taxas de participação percentual no GPC quando comparado com as demais grandes áreas geográficas, o volume de inscrições se manteve estável, representando conjuntamente 7\% em 1996 e os mesmos $7 \%$ em 2003.

Antes que estes percentuais levem a conclusões sobre o Sul do país em relação ao Norte, é importante relativizar esta distribuição em termos de número de jurisdições em cada região geográfica. No Sul e Sudeste (estados do RS, SC, PR, SP, RJ, ES e MG) concentram-se 2.825 municípios, o equivalente a $51 \%$ do total de cidades do país. Por outro lado, no Centro-Oeste e Norte (estados do MT, MS, GO, AC, AM, RO, RR, AP, TO e PA) se encontram 894 cidades, o que representa 16\% dos 5.506 municípios brasileiros. No Nordeste (estados do MA, PI, CE, RN, PB, PE, AL, SE e BA) existem 1.787 cidades, o que corresponde a $32 \%$ do total do país. Conseqüentemente, mesmo diante de uma maior representação do Sul e Sudeste no GPC, não se trata de uma diferença tão exagerada. Essa questão será examinada com mais detalhes na Tabela 4, na qual se demonstra o peso das inscrições municipais em proporção à quantidade de municípios existentes em cada Estado.

Na tabela 3 é destacada a informação acerca do volume de inscrições enviadas pelos diferentes municípios que participaram dos ciclos de premiação no período de 1996 a 2003. Ressalta-se que está sendo computada apenas a participação individual de cada município, sem levar em consideração a quantidade de inscrições enviadas por cada um deles. 
TABELA 3 - Número Total dos diferentes municípios participantes segundo a região de origem $(1996$ - 2003)

\begin{tabular}{|c|c|c|}
\hline Região & Municípios Inscritos & $(\%)$ \\
\hline Centro-Oeste & 34 & 4 \\
\hline Nordeste & 130 & 17 \\
\hline Norte & 38 & 5 \\
\hline Sudeste & 354 & 45 \\
\hline Sul & 228 & 29 \\
\hline Total & 784 & \\
\hline
\end{tabular}

: exclui o Distrito Federal

As informações contidas na tabela 3 revelam que 784 diferentes municípios já participaram em pelo menos um dos oito ciclos do Programa Gestão Pública e Cidadania. Destaca-se, também, a existência de 22 municípios participando ininterruptamente de todos os ciclos de premiação do Gestão Pública e Cidadania que têm sido realizados desde 1996. Algumas dessas cidades mesmo não figurando entre as finalistas em pelo menos um dos ciclos de premiação, continuam inscrevendo os seus programas pelo fato de o GPC também representar uma boa estratégia de disseminação das iniciativas que estão sendo desenvolvidas pelos seus governos. São os casos de: Bauru (SP); Lins (SP); Campo Grande (MS) e Campo Mourão (PR) ${ }^{2}$.

No mapa adiante destaca-se a distribuição geográfica dos 784 diferentes municípios que participaram em pelo menos um dos ciclos de premiação do Programa Gestão Pública e Cidadania. Ressalta-se que está sendo computada apenas a participação individual de cada cidade independentemente da quantidade de inscrições enviadas por cada um dos municípios.

\footnotetext{
2 Os municípios que participam do GPC desde 1996 e que já foram finalistas em pelo menos um Ciclo de Premiação são: Belém (PA); Belo Horizonte (MG); Brasília (DF); Campinas (SP); Curitiba (PR); Diadema (SP); Fortaleza (CE); Ipatinga (MG); Juiz de Fora (MG); Lages (SC); Londrina (PR); Porto Alegre (RS); Santos (SP); São Bernardo do Campo (SP); São José dos Campos (SP); São Paulo (SP); Teresina (PI); e Vitória (ES).
} 


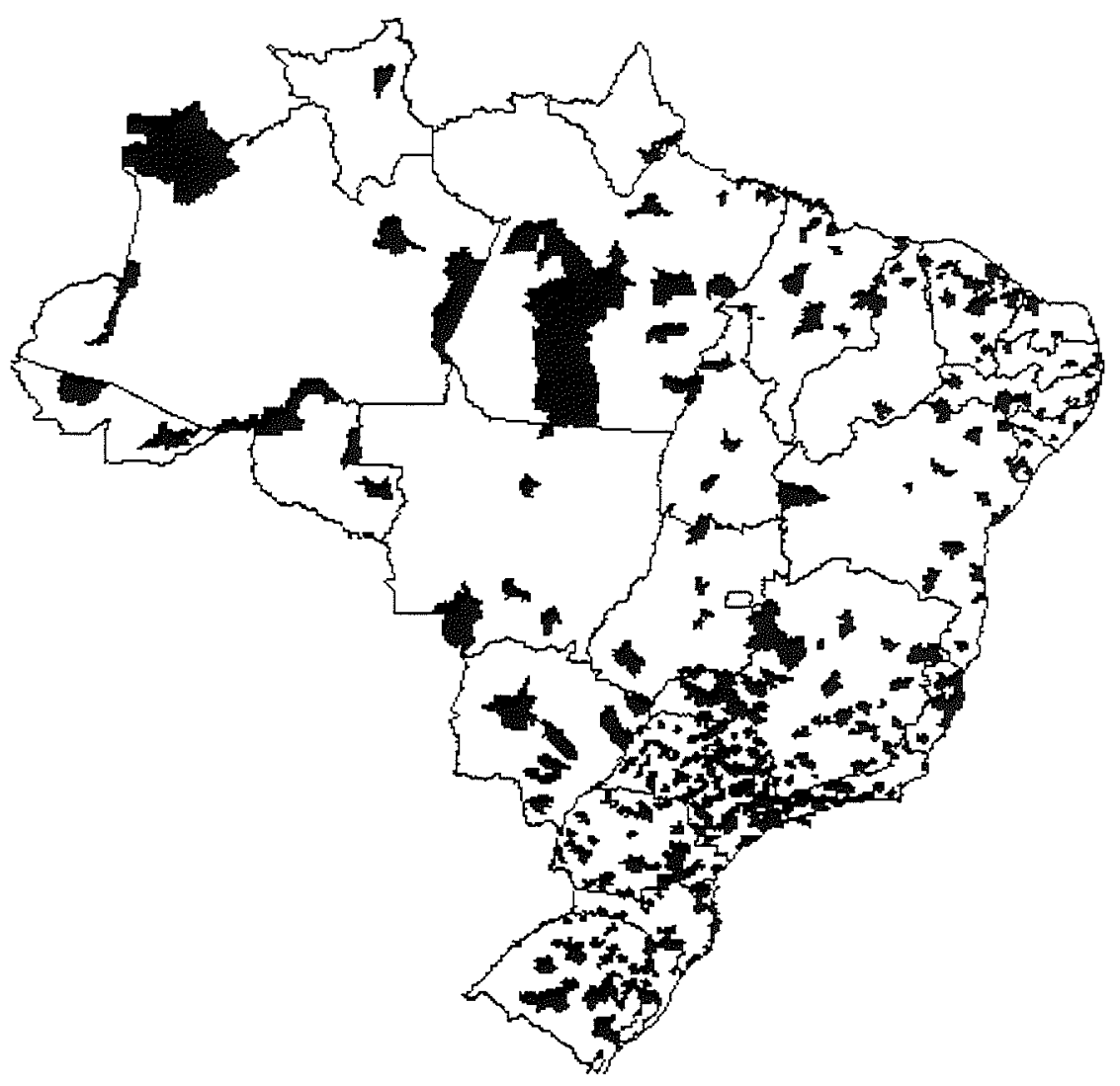

No mapa acima é possível constatar a presença do GPC em todo o território nacional com maior concentração nas regiões Sul e Sudeste. Porém, quando se analisa a participação proporcional dos diferentes municípios segundo o Estado de origem desde 1996, observa-se que alguns estados localizados em regiões menos populosas e com baixo desenvolvinento industrial aparecem com destaque, como é demonstrado na tabela 4. Os dados relativos ao número de diferentes municípios inscritos em relação ao total de municípios por Unidade Federativa revelam que o estado de São Paulo foi o que proporcionalmente contribuiu com o maior número de cidades inscritas nesses oito anos de GPC. Na seqüência aparecem, respectivamente, os estados do Rio Janeiro, Rio Grande do Sul, Santa Catarina, Espírito Santo, Acre, Paraná, Ceará e Sergipe. Em 20 estados, a presença de municípios no Ciclo de Premiação do Programa Gestão Pública e Cidadania já é superior a $10 \%$. 
TABELA 4 - Inscrições por município em proporção ao número de municípios por Estado (1996 - 2003)

\begin{tabular}{|c|c|c|c|}
\hline Estados & $\begin{array}{l}\text { Total de } \\
\text { municípios }\end{array}$ & $\begin{array}{c}\text { N.o de } \\
\text { municípios } \\
\text { que efetuaram } \\
\text { a inscrição }\end{array}$ & $\begin{array}{c}\text { Participação } \\
\text { proporcional } \\
(\%)\end{array}$ \\
\hline SP & 645 & 195 & 30,2 \\
\hline RJ & 91 & 27 & 29,6 \\
\hline RS & 467 & 108 & 23,1 \\
\hline ES & 77 & 16 & 20,8 \\
\hline SC & 293 & 55 & 18,8 \\
\hline $\mathrm{AC}$ & 22 & 4 & 18,1 \\
\hline $\mathrm{PR}$ & 399 & 70 & 17,5 \\
\hline $\mathrm{CE}$ & 184 & 31 & 16,9 \\
\hline SE & 75 & 12 & 16 \\
\hline MS & 77 & 11 & 14,2 \\
\hline RR & 15 & 2 & 13,3 \\
\hline $\mathrm{MG}$ & 853 & 112 & 13,1 \\
\hline MT & 126 & 16 & 12,7 \\
\hline $\mathrm{PE}$ & 185 & 22 & 11,9 \\
\hline PA & 143 & 16 & 11,2 \\
\hline AM & 62 & 6 & 9,7 \\
\hline RO & 52 & 5 & 9,6 \\
\hline $\mathrm{AP}$ & 16 & 1 & 6,2 \\
\hline $\mathrm{MA}$ & 217 & 13 & 6 \\
\hline $\mathrm{BA}$ & 415 & 23 & 5,5 \\
\hline PB & 223 & 11 & 4,9 \\
\hline $\mathrm{AL}$ & 101 & 4 & 4 \\
\hline TO & 139 & 5 & 3,6 \\
\hline $\mathrm{PI}$ & 221 & 7 & 3,2 \\
\hline RN & 166 & 5 & 3 \\
\hline $\mathrm{GO}$ & 242 & 7 & 2,9 \\
\hline Total & 5506 & 784 & 14,2 \\
\hline
\end{tabular}

Na tabela 5 é apresentada a distribuição dos 784 diferentes municípios que participaram do Gestão Pública e Cidadania entre 1996 e 2003, segundo o porte populacional. 
TABELA 5 - Distribuição dos diferentes municípios que participaram dos ciclos de premiação do GPC entre 1996-2003, segundo o porte populacional

\begin{tabular}{|c|c|c|c|c|c|c|}
\hline População & $\begin{array}{c}\text { n. }{ }^{\circ} \text { de } \\
\text { municípios } \\
\text { participantes } \\
\text { do GPC }\end{array}$ & $\begin{array}{c}\text { (\%) no } \\
\text { GPC }\end{array}$ & $\begin{array}{l}\text { população } \\
\text { dos } \\
\text { diferentes } \\
\text { municípios } \\
\text { inscritos }\end{array}$ & $\begin{array}{l}\mathrm{n}^{\circ} \text { total de } \\
\text { municípios } \\
\text { brasileiros }\end{array}$ & $(\%)$ & $\begin{array}{c}\text { população } \\
\text { dos } \\
\text { municípios }\end{array}$ \\
\hline Até 20.000 & 309 & 39,3 & 2.954 .441 & 4.019 & 72,8 & 33.437 .404 \\
\hline 20.001 a 50.000 & 180 & 22,9 & 5.741 .109 & 964 & 17.5 & 28.832 .600 \\
\hline 50.001 a 100.000 & 120 & 15,3 & 8.662 .820 & 301 & 5.5 & 20.928 .128 \\
\hline 100.001 a 200.000 & 83 & 10,6 & 11.731 .442 & 117 & 2.1 & 16.406 .325 \\
\hline 200.001 a 500.000 & 64 & 8,1 & 19.256 .729 & 76 & 1.4 & 23.221 .680 \\
\hline 500.001 a 1.000 .000 & 16 & 2,1 & 10.887 .858 & 18 & 0.4 & 12.583 .713 \\
\hline Acima de $1.000 .001^{*}$ & 12 & 1,7 & 34.389 .320 & 12 & 0.3 & 34.389 .320 \\
\hline Total & 784 & & 91.572 .573 & 5.506 & & 167.748 .024 \\
\hline
\end{tabular}

Na tabela acima é possível verificar que os municípios com até 20.000 habitantes contribuíram com 39,3\% de todas as inscrições enviadas pelas diferentes cidades no período de 1996 a 2003. Os municípios cujo contingente populacional está entre 20.0001 e 100.000 habitantes representaram 38,2\% de todos os inscritos nesse mesmo período. Dessa maneira, a participação percentual das cidades com até 100.000 habitantes nesses oito anos do Programa Gestão Pública e Cidadania foi de 77,5\%.

A existência de um significativo número de micros, pequenos e médios municípios que identificam as suas iniciativas como inovadoras e as inscrevem no Ciclo de Premiação do Gestão Pública e Cidadania é muito importante na medida em que as políticas desenvolvidas nas cidades de pequeno porte tendem a ser mais universalizantes do que as executadas nas grandes cidades, visto que a pequena dimensão territorial e o porte populacional dessas localidades permitem a elaboração de iniciativas de alcance social mais amplo.

Por outro lado, apesar da expressiva participação de cidades de menor porte, verifica-se que ainda é necessário estimular tais localidades a inscreverem suas iniciativas no Ciclo de Premiação do Programa Gestão Pública e Cidadania. Dos 4.019 municípios brasileiros 
com até 20.000 habitantes, somente $309(7,7 \%)$ enviaram inscrições para o GPC no período destacado.

A presença de municípios no Ciclo de Premiação do Programa Gestão Pública $e$ Cidadania é maior na medida em que o porte populacional da cidade aumenta. Das cidades com faixa populacional entre 20.001 e 50.000 habitantes, $18,8 \%$ já participaram do GPC; entre as que estão na faixa populacional entre 50.001 e 100.000 moradores, o percentual de participação foi de 39,9\%; entre os municípios com 100.001 e 200.000 habitantes a porcentagem de inscritos no GPC alcançou 70,9\%; nas cidades cuja população oscila entre 200.001 e 500.000 pessoas, $84,2 \%$ já inscreveram suas iniciativas no Programa Gestão Pública e Cidadania; já nas localidades cuja população é superior a 500.001 e inferior a 1.000 .000 de habitantes, 88,9\% já estiveram no GPC, enquanto todos os 12 municípios brasileiros com população acima de um milhão de pessoas já participaram de pelo menos um dos ciclos de premiação.

A tabela 6 apresenta a distribuição do total de inscritos em 2003, segundo a região geográfica.

TABELA 6 - Distribuição do total dos inscritos em 2003 por região geográfica

\begin{tabular}{lcc}
\hline Região & N.o Inscritos & (\%) \\
\hline Centro Oeste & 31 & 3 \\
\hline Nordeste & 195 & 17 \\
\hline Norte & 41 & 4 \\
Sudeste & 520 & 45 \\
Sul & 369 & 32 \\
\hline Total & 1156 & \\
\hline
\end{tabular}

Como se verifica na tabela 6, no ano de 2003 a maior parte das iniciativas inscritas no GPC foram provenientes das regiões Sudeste e Sul. Porém, quando se compara com a distribuição regional das experiências inscritas em 2002 (ver tabela 2), constata-se uma queda na participação relativa das regiões sudeste (de 51\% em 2002 para 45\% em 2003) e Centro Oeste (de 6\% em 2002 para 3\% em 2003), e um aumento da participação das regiões Sul (de $26 \%$ em 2002 para 32\% em 2003) e Nordeste (de 13\% em 2002 para $17 \%$ em 2003).

Na próxima tabela destaca-se a distribuição regional dos diferentes municípios que enviaram inscrições para o Ciclo de Premiação de 2003. 
TABELA 7 - Número total dos diferentes municípios com programas inscritos no ano de 2003 segundo a região geográfica

\begin{tabular}{lcc}
\hline Região & N.o Inscritos & $(\%)$ \\
\hline Centro Oeste & 12 & 4 \\
\hline Nordeste & 55 & 18 \\
\hline Norte & 11 & 3 \\
\hline Sudeste & 146 & 45 \\
\hline Sul & 96 & 30 \\
\hline Total & 320 & \\
\hline * exclui Distrito Federal & &
\end{tabular}

Da mesma forma que se verificou na tabela 6 quando os dados relativos ao número total de inscritos demonstraram a prevalência de inscrições oriundas das regiões Sudeste e Sul com $77 \%$ do total, ao se dividir os diferentes municípios inscritos por região geográfica, $75 \%$ das cidades que enviaram inscrições para o GPC em 2003 também estão localizadas nas regiões Sudeste e Sul. Nas demais regiões, os dados acerca dos diferentes municípios inscritos são praticamente iguais aos verificados com o total de experiências enviadas por todos os governos subnacionais.

Porém, como pode ser visto na próxima tabela, quando se compara o número de diferentes municípios inscritos no GPC proporcionalmente ao total de cidades de cada Estado, alguns estados de menor dimensão populacional surgem com maior destaque, conforme também foi visto na tabela 4.

Na próxima tabela constata-se que em 24 dos 26 estados brasileiros houve municípios que inscreveram seus programas, projetos ou práticas no Ciclo de Premiação do Programa Gestão Pública e Cidadania em 2003. Apenas os estados do Amapá e Alagoas não tiveram municípios participantes. Também se destaca o fato de, proporcionalmente, Roraima aparecer como o Estado com maior participação percentual na relação entre o número de municípios inscritos no GPC e o total de cidades do Estado, seguido por Rio de Janeiro, São Paulo, Rio Grande do Sul, Santa Catarina e Ceará. Ao todo, em 10 estados o volume de participação percentual dos municípios foi de 5\% ou mais. 
TABELA 8 - Inscrições por município em proporção ao $n^{\circ}$ de municípios por Estado (2003)

\begin{tabular}{lccc}
\hline Estados & $\begin{array}{c}\text { Total de } \\
\text { municípios }\end{array}$ & $\begin{array}{c}\text { N. }{ }^{\circ} \text { de } \\
\text { micípios que } \\
\text { efetuaram } \\
\text { inscrições }\end{array}$ & $\begin{array}{c}\text { Participação } \\
\text { proporcional } \\
(\%)\end{array}$ \\
RR & 15 & 2 & 13,3 \\
RJ & 91 & 12 & 13,2 \\
SP & 645 & 84 & 13,0 \\
RS & 467 & 50 & 10,7 \\
SC & 293 & 27 & 9,2 \\
CE & 184 & 16 & 8,6 \\
PE & 185 & 10 & 5,4 \\
MG & 853 & 45 & 5,3 \\
\hline ES & 77 & 4 & 5,2 \\
\hline PR & 399 & 20 & 5,0 \\
\hline AC & 22 & 1 & 4,5 \\
PA & 143 & 6 & 4,2 \\
\hline MT & 126 & 5 & 4,0 \\
SE & 75 & 3 & 4,0 \\
\hline MS & 77 & 3 & 3,9 \\
\hline MA & 217 & 7 & 3,2 \\
\hline RN & 166 & 4 & 2,4 \\
\hline BA & 415 & 8 & 1,9 \\
\hline RO & 52 & 1 & 1,9 \\
\hline PB & 223 & 4 & 1,8 \\
\hline GO & 242 & 4 & 1,7 \\
\hline AM & 62 & 1 & 1,6 \\
\hline PI & 221 & 2 & 1,0 \\
\hline TO & 139 & 1 & 1,0 \\
\hline Total & 5506 & 320 & 5,8 \\
\hline$*$ exclui o Distrito Federal & & \\
\hline
\end{tabular}

A próxima tabela indica a distribuição dos diferentes municípios inscritos em 2003 , segundo o porte populacional. 
TABELA 9 - Distribuição dos diferentes municípios que participaram dos ciclos de premiação do GPC em 2003 segundo o porte populacional

\begin{tabular}{lcccccc}
\hline População & $\begin{array}{c}\text { n. }{ }^{\circ} \text { de } \\
\text { municípios } \\
\text { participantes } \\
\text { do GPC }\end{array}$ & $\begin{array}{c}\text { (\%) no } \\
\text { GPC }\end{array}$ & $\begin{array}{c}\text { população } \\
\text { dos diferentes } \\
\text { municípios } \\
\text { inscritos }\end{array}$ & $\begin{array}{c}\text { n. }^{\circ} \text { total de } \\
\text { municípios } \\
\text { brasileiros }\end{array}$ & (\%) & $\begin{array}{c}\text { população dos } \\
\text { municípios }\end{array}$ \\
\hline Até 20.000 & 90 & 28 & 902.352 & 4.019 & 72,8 & 33.437 .404 \\
\hline 20.001 a 50.000 & 59 & 18 & 1.869 .288 & 964 & 17.5 & 28.832 .600 \\
\hline 50.001 a 100.000 & 61 & 19 & 4.476 .487 & 301 & 5.5 & 20.928 .128 \\
\hline 100.001 a 200.000 & 47 & 15 & 6.542 .116 & 117 & 2.1 & 16.406 .325 \\
\hline 200.001 a 500.000 & 43 & 14 & 13.444 .137 & 76 & 1.4 & 23.221 .680 \\
\hline 500.001 a 1.000 .000 & 10 & 3 & 6.828 .680 & 18 & 0.4 & 12.583 .713 \\
\hline Acima de $1.000 .001 *$ & 10 & 3 & 29.859 .622 & 12 & 0.3 & 34.389 .320 \\
\hline Total & 320 & & 63.922 .682 & 5.506 & & 167.748 .024 \\
\hline
\end{tabular}

* Exclui o Distrito Federal.

Os dados relativos ao $n^{\circ}$ total de municípios brasileiros e população são do Censo/2000 do IBGE.

Os dados da tabela 9 demonstram que dentre as 320 cidades inscritas em 2003, 28\% possuem até 20.000 moradores, percentual inferior ao total de $39 \%$ verificado para o mesmo porte populacional quando são analisados os 784 diferentes municípios inscritos no GPC desde 1996 (ver tabela 5). Observa-se ainda que, na medida em que aumenta o porte populacional dos municípios, maior é a participação proporcional das cidades quando comparadas com o total existente no país segundo o porte populacional.

Dentre os municípios com até 20.000 habitantes inscritos no Ciclo de Premiação 2003 destacam-se: Serra da Saudade (MG), 873 moradores; Lagoa dos Três Cantos (RS), 1.627 habitantes; Prata (PB), 3.425 moradores; Uiramutã (RR), 5.802 habitantes; e Sapezal (MT) com uma população total de 7.862 pessoas.

A tabela 10 demonstra a divisão dos programas inscritos no Ciclo de Premiação 2003, segundo a área de atuação. 


\begin{tabular}{|c|c|c|}
\hline \multicolumn{3}{|c|}{$\begin{array}{c}\text { TABELA } 10 \text { - Programas Inscritos em } 2003 \text { Segundo as Grandes } \\
\text { Áreas de Atuação Governamental }\end{array}$} \\
\hline Áreas de Atuação & N.o Inscritos & $(\%)$ \\
\hline Serviços Públicos & 560 & 48 \\
\hline Cidadania e Direitos Humanos & 255 & 22 \\
\hline Desenvolvimento Econômico e Social & 143 & 12 \\
\hline Infra-estrutura e Meio Ambiente & 100 & 9 \\
\hline Administração e Governo & 89 & 8 \\
\hline Judiciário & 5 & 0 \\
\hline Legislativo & 4 & 0 \\
\hline Total & 1156 & \\
\hline
\end{tabular}

Na tabela 10 é possível verificar a concentração de inscrições na área de Serviços Públicos com um total de $48 \%$ de todas os inscrições. Isso reflete a presença significativa das demandas sociais nas subáreas de Educação, Saúde e Assistência Social, como poderá ser constatada na tabela 12. Na seqüência aparecem áreas com grande importância para a gestão pública como: Cidadania-e Direitos Humanos, Desenvolvimento Econômico e Social, e Infraestrutura e Meio Ambiente.

O Judiciário e o Legislativo continuam apresentando uma baixa taxa de participação no GPC. A próxima tabela demonstra a distribuição das inscrições por Área de Atuação Governamental, segundo a região geográfica.

TABELA 11 - Programas Inscritos em 2003, por Área de Atuação Governamental, Segundo a Região Geográfica

\begin{tabular}{|c|c|c|c|c|c|c|c|c|c|c|}
\hline \multirow[t]{2}{*}{ Área } & \multicolumn{2}{|c|}{$\begin{array}{c}\text { Centro } \\
\text { Oeste }\end{array}$} & \multicolumn{2}{|c|}{ Nordeste } & \multicolumn{2}{|c|}{ Norte } & \multicolumn{2}{|c|}{ Sudeste } & \multicolumn{2}{|c|}{ Sul } \\
\hline & n.a & $\%$ & n.a & $\%$ & n.a & $\%$ & & $\%$ & n.a & $\%$ \\
\hline Administração e Governo & 5. & 13 & 16 & 8 & 3 & 10 & 38 & 7 & 27 & 7 \\
\hline Infra-Estrutura e Meio Ambiente & 1 & 3 & 14 & 7 & 0 & & 52 & 10 & 33 & 9 \\
\hline Serviços Públicos & 22 & 55 & 94 & 48 & 14 & 45 & 229 & 44 & 201 & 55 \\
\hline Cidadania e Direitos Humanos & 11 & 28 & 44 & 23 & 8 & 26 & 130 & 25 & 62 & 17 \\
\hline Desenvolvimento Econômico e Social & 1 & 3 & 27 & 14 & 5 & 16 & 67 & 13 & 42 & 11 \\
\hline Legislativo & 0 & & 0 & & 0 & & 2 & 0 & 2 & 1 \\
\hline Judiciário & 0 & & 0 & & 1 & 3 & 3 & 1 & 1 & 0 \\
\hline Total & 40 & & 195 & & 31 & & 521 & & 368 & \\
\hline
\end{tabular}

Nos dados da tabela 11 verifica-se a participação proporcional das inscrições por Área de Atuação Governamental em cada região geográfica. As iniciativas na área de Serviços Públicos estão mais presentes nas experiências oriundas do Centro-Oeste e do Sudeste 
brasileiro. As questões relativas a Infra-estrutura e Meio Ambiente alcançam maior peso no Sudeste, Sul e Nordeste, regiões que apresentam maiores taxas de concentração de população urbana e também de problemas ambientais. Por outro lado, no Norte e no Centro Oeste, onde se concentra a maior parte da biodiversidade brasileira, a participação de inscrições em Infra-estrutura e Meio Ambiente inexiste (no caso da região Norte) ou é residual (no caso da Centro-Oeste).

Destaca-se ainda que as iniciativas da Área Cidadania e Direitos Humanos distribuem-se de maneira muito parecida por todas as regiões: $26 \%$ na região Norte; $28 \%$ na CentroOeste; $25 \%$ na Sudeste; $17 \%$ na Sul; e $23 \%$ na Nordeste. Quando se trata de Desenvolvimento Econômico e Social, as inscrições demonstram que essa é uma preocupação de todas as regiões brasileiras, a maior incidência percentual encontra-se no Nordeste $(16 \%)$ e a menor no Centro-Oeste (3\%).

A tabela 12 ilustra a distribuição geral dos programas inscritos segundo as Subáreas de Atuação Governamental.

Ao observar a tabela, constata-se que as subáreas Educação, Saúde e Assistência Social, todas integrantes da Área de Serviços Públicos, foram responsáveis por 37,3\% de todos os programas e projetos inscritos. A subárea de Criança e Adolescente, incluída na área de Cidadania e Direitos Humanos, aparece com 13,3\% das inscrições. Desse modo, essas quatro subáreas representaram 50,6\% dos inscritos em 2003. Tais dados demonstram a preocupação dos gestores na elaboração de políticas públicas voltadas para a resolução dos problemas existentes nessas áreas, assim como também expressam a existência de uma grande pressão social por iniciativas públicas voltadas para o enfrentamento de problemas relativos aos serviços públicos e à criança e ao adolescente. 
TABELA 12 - Programas Inscritos em 2003 Segundo as Subáreas de Atuação Governamental

\section{Subárea}

Educação

Criança e Adolescente

Saúde

Assistência Social

Formação de Mão-de-Obra e Geração de Emprego e Renda

Cultura e Patrimônio Histórico e Artístico

Lazer e Esportes

Desenvolvimento Regional e Local em Bases Sustentáveis

Formas de Gestão e Planejamento $\quad 2,7$

Idoso

Participação Popular

Limpeza Pública e Sistemas de Coleta, Tratamento e Destinação Final de Lixo

Agropecuária e Pesca

Deficiente

Mulher

Habitação

Preservação de Ecossistemas e Reflorestamento $\quad 1,3$

Saneamento (água e esgoto)

Melhoria das Condições e Relações de Trabalho 1,0

Desenvolvimento e Administração Pessoal $\quad 0,8$

Sistemas de Informação $\quad 0,8$

Urbanismo, Uso e Ocupação do Solo $\quad 0,7$

Trânsito e Vias Públicas 0,5

Prevenção de Acidentes em Áreas de Risco $\quad 0,5$

Minorias 0,5

$\begin{array}{lr}\text { Segurança Pública e Policiamento } & 0,4\end{array}$

Controle de Poluição $\quad 0,3$

Ciências e Tecnologia $\quad 0,3$

Reforma Agrária $\quad 0,3$

Sistema de Fiscalização e Controle $\quad 0,3$

Energia e Recursos Minerais 0,3

Recursos Hídricos, Irrigação e Drenagem $\quad 0,3$

Negro $\quad 0,3$

Relações Intragovernamentais $\quad 0,2$

Transporte Público $\quad 0,2$

Indústria, Comércio e Serviços $\quad 0,2$

Relações Intergovernamentais $\quad 0,1$

Patrimônio Público $\quad 0,1$

Consórcios Intermunicipais $\quad 0,1$

Abastecimento $\quad 0,1$

Consumidor $\quad 0,1$

Outros 6,4

\begin{tabular}{lr} 
Total & 100 \\
\hline
\end{tabular}


A tabela 13 aponta por quais partidos foram eleitos os prefeitos dos 320 diferentes municípios que participaram do Ciclo de Premiação 2003 do Programa Gestão Pública e Cidadania.

TABELA 13 - Partidos dos Prefeitos de Municípios que Participaram do Ciclo de Premiação 2003

\begin{tabular}{lccc}
\hline Partido & $\begin{array}{c}N^{\circ} \text { Prefeituras } \\
\text { Inscritas no Ciclo }\end{array}$ & $\begin{array}{c}\mathrm{N}^{\circ} \text { Prefeituras sob } \\
\text { Responsabilidade do } \\
\text { Partido no País }\end{array}$ & $\begin{array}{c}\text { Relação } \text { N }^{\circ} \text { Inscritos / } \\
\mathrm{N}^{\circ} \text { no País (\%) }\end{array}$ \\
PT & 2003 & 187 & 28,3 \\
\hline PDT & 53 & 288 & 9,4 \\
\hline PPS & 27 & 166 & 7,8 \\
\hline PSB & 13 & 133 & 7,5 \\
\hline PSDB & 10 & 990 & 6,4 \\
\hline PP* & 64 & 618 & 6,3 \\
\hline PSD & 39 & 111 & 6,3 \\
\hline PFL & 7 & 1028 & 3,6 \\
PMDB & 37 & 1257 & 3,5 \\
\hline PTB & 43 & 398 & 3,5 \\
PL & 14 & 234 & 2,6 \\
\hline Outros & 6 & 97 & 7,2 \\
\hline Total & 7 & 5506 & 5,8 \\
\hline
\end{tabular}

* Nova denominação do PPB.

Os atuais prefeitos foram eleitos no ano 2000 .

Os dados acima revelam que os 320 municípios que se inscreveram no Ciclo de Premiação 2003 estão sendo administrados pelos diferentes partidos que compõem a arena política brasileira. Desse modo, a idéia de inovação assume um caráter multipartidário e perpassa a questão ideológica ao ser reivindicada tanto por partidos considerados de direita como pelos de esquerda.

Ao juntar gestores de origem partidária tão distintas num mesmo Ciclo de Premiação, o Programa Gestão Pública e Cidadania demonstra que está conseguindo estabelecer diálogo com os mais diversos segmentos políticos que estão à frente dos governos subnacionais brasileiros. 
Ao analisar a distribuição proporcional dos municípios inscritos no Ciclo 2003 por partido, é possível constatar que as agremiações partidárias consideradas de centro-esquerda acabam demonstrando maior sensibilidade em estimular os seus prefeitos a participar do Ciclo de Premiação. Legendas partidárias como o PT, PDT, PPS, PSB e PSDB, todas identificadas como de centro-esquerda, possuem, proporcionalmente ao número de prefeituras que controlam, o maior número de prefeitos à frente de municípios que se inscreveram no GPC.

É importante destacar que dentre os inscritos é possível não apenas encontrar programas inovadores em municípios dirigidos pelos mais diversos partidos, como também experiências de consórcios intermunicipais que aglutinam gestores públicos de diversas origens políticas que buscam juntar forças para enfrentar problemas comuns a seus municípios. Por exemplo, o Consórcio Lambari (um programa de gestão participativa do meio ambiente que reúne 15 municípios da região do Alto Uruguai catarinense) envolve dentre outras cidades: Arvoredo, cujo prefeito foi eleito pelo PMDB; Concórdia, administrada pelo PT; Lindóia do Sul, dirigida por um prefeito eleito pelo PFL; e Seara, município cujo gestor público se elegeu pelo PPB (hoje denominado PP).

Também no Estado de Santa Catarina o Programa de Melhoramento de Campos Naturais do Planalto Catarinense (Consórcio Intermunicipal voltado para o desenvolvimento de políticas de manejo adequado do solo utilizado para a pecuária) agrega municípios administrados por prefeitos filiados a diferentes partidos, mas que superaram suas divergências políticas ao se unirem em prol da melhoria da qualidade de vida local. Os municípios reunidos em torno de tal iniciativa são: Bom Retiro, cujo prefeito foi eleito pelo PDT; Lages, onde gestor municipal é filiado ao PFL; Rancho Queimado, cujo chefe do Executivo pertence aos quadros do PMDB, São Joaquim, cuja administração municipal é dirigida por um membro do PFL; e o município de Urubuci, onde o prefeito local se elegeu pelo PPB.

Por fim, vale ressaltar que existem programas voltados para a inclusão social e para o desenvolvimento sustentável que foram formulados por gestores filiados aos mais diversos partidos e que estão servindo de modelo para que experiências semelhantes sejam desenvolvidas em outros locais. Isso demonstra que as boas práticas públicas podem ser replicadas com as devidas adequações nos mais diferentes lugares, mesmo que elas estejam fortemente identificadas, na sua origem, com algum partido político. 


\section{Bibliografia consultada}

BELTRÃO, Ricardo Ernesto Vasquez; FARAH, Marta Ferreira Santos \& LACZYNSKI, Patrícia. "Um primeiro olhar sobre o Ciclo de Premiação 1998". In: BELTRÃO, Ricardo Ernesto Vasquez; MAURO, Carlos Eduardo Evangelisti \& LACZYNSKI, Patrícia (org.). Cadernos Gestão Pública e Cidadania (A administração pública brasileira inovando a forma de governar: apresentação dos 631 programas inscritos no Ciclo de Premiação 1998). São Paulo: EAESP-FGV, v.12, 1998, p.7-19.

FARAH, Marta Ferreira Santos. Governo Local, Políticas Públicas e Novas Formas de Gestão Pública no Brasil . Organizações e Sociedade, Salvador: v.7, n. 17, jan./abr.2000, p.5986.

FARAH, Marta Ferreira Santos \& BELTRÃO, Ricardo Ernesto Vasquez. "Perfil dos programas inscritos em "1997". In: BELTRÃO, Ricardo Ernesto Vasquez (org.). Cadernos Gestão Pública e Cidadania (A administração pública brasileira inovando a forma de governar: apresentação dos 297 programas inscritos no Ciclo de Premiação 1997). São Paulo: EAESP-FGV, v.8, 1996, p.7-14.

FARAH, Marta Ferreira Santos. "Que está mudando na gestão pública brasileira? Tendência sugeridas pelos programas inscritos". In: BELTRÃO, Ricardo Ernesto Vasquez (org.). Cadernos Gestão Pública e Cidadania (A administração pública brasileira inovando a forma de governar - Ciclo de Premiação 1996). São Paulo: EAESP-FGV, v.1, 1996, p.716.

FUNDAÇÃO INSTITUTO BRASILEIRO DE GEOGRAFIA E ESTATÍSTICA - IBGE. Censo Demográfico 2000. Rio de Janeiro: IBGE, 2001.

LACZYNSKI, Patrícia, BELTRÃO, Ricardo Ernesto Vasquez \& FARAH, Marta Ferreira Santos. "Uma breve análise do Ciclo de Premiação 1999". In: LACZYNSKI, Patrícia., BARACCHINI, Sabrina Addison \& BELTRÃO, Ricardo Ernesto Vasquez (org.). Cadernos Gestão Pública e Cidadania (A administração pública brasileira inovando a forma de governar: apresentação dos 888 programas inscritos no Ciclo de Premiação 1999). São Paulo: EAESP-FGV, v.16, 1999, p.7-16. 
LACZYNSKI, Patrícia; AROUCA, Francine Lemos \& FUJIWARA, Luis Mário. "O que há de novo no Programa Gestão Pública e Cidadania". In: PETER, Spink; LACZYNSKI, Patrícia \& AROUCA, Francine Lemos (orgs.). A administração pública brasileira inovando a forma de governar: apresentação dos 728 programas inscritos no Ciclo de Premiação 2001. São Paulo: EAESP-FGV, v.21, 2001, p.7-17.

SPINK, Peter; Arouca, Francine Lemos; Teixeira, Marco Antonio. A administração pública brasileira inovando a forma de governar: apresentação dos 981 programas inscritos no Ciclo de Premiação 2002. São Paulo: EAESP-FGV, v.22, 2002.

SPINK, Peter. The Rights Approach to Local Public Management: experiences from Brazil. Revista de Administração de Empresas. São Paulo: v.40, n.3, jul./set.2000, p.45-65.

SPINK, Peter. Gestão Municipal faz escola: aprendendo com os governos locais. Cadernos Adenauer: os municípios e as eleições de 2000. São Paulo: n.4, jun.2000.

SPINK, Peter; CLEMENTE, Roberta \& KEPPKE, Rosane. Governo local: o mito e as novas práticas de governança. Revista de Administração. São Paulo: v.34, n.1, jan./mar.1999, p.61-9. 